\title{
Evacuation and Community Issues Caused by Nuclear Disaster in Fukushima Japan
}

\author{
Akira Takagi (Corresponding author) \\ Department of Social Environment and Welfare \\ Kumamoto Gakuen University \\ 2-5-1 Oe, Chuo-ku, Kumamoto 862-8680, Japan \\ Tel: 81-96-364-5161Ｆax: 81-96-363-1289Ｅ-mail: takira@kumagaku.ac.jp
}

Received: January 10, 2017 Accepted: January 10, 2017 Published: February 28, 2017 doi:10.5296/jad.v3i1.10578 URL: http://dx.doi.org/10.5296/jad.v3i1.10578

\begin{abstract}
The aim of this study is to clarify the evacuation behaviors of the local residents in a small rural community called "T" district in Iwaki City, Fukushima Prefecture at the Great East Japan Earthquake (GEJE) on March 11th, 2011 and how their personal relationship changed subsequently. This district suffered more impact from the nuclear disaster caused by Tokyo Electrical Power Company Fukushima Daiichi Nuclear Power Station (TEPCO-1F NPS) accident than from the earthquake itself: a split in the community arising from the residents' various evacuation behaviors and disagreement in their attitudes toward radioactivity. For example, a serious conflict occurred between those who returned from out-of-district evacuation ("escapees") and those who consistently stayed within the district ("non-escapees"). However, on the other hand, as a way to maintain their community functions, there was an attempt made by the returnees inside the community in order to temper the conflict and another attempt provided from outside of the community such as the re-start of university student experience program which had been carried out by the local residents before the GEJE. Now that nearly 6 years have passed since the occurrence of the GEJE, the community conflict is becoming less obvious but not yet completely solved.
\end{abstract}

Keywords: great earthquake, nuclear disaster, March 11 2011, Japan, Fukushima Prefecture, evacuation, community 


\section{Introduction}

The purpose of this study is to clarify how people's decision making and evacuation behaviors vary at occurrence of a massive disaster, and also how their community changes over time. The Great East Japan Earthquake (GEJE), which struck Tohoku Region (Note 1) of Japan on March 11th, 2011, caused a tsunami and a nuclear disaster. Particularly, the accident which occurred in Tokyo Electrical Power Company Fukushima Daiichi Nuclear Power Station (TEPCO-1F NPS) was so serious that it was judged as an accident of Level 7 by IAEA Safety Standards. In this accident, the radioactive substances emitted from TEPCO-1F NPS contaminated a wide swath of Kanto Region (Note 2), centering around certain parts of Fukushima Prefecture.

Because of the earthquake, the tsunami, and the nuclear disaster, the maximum of 164865 people out of the total population of 3000000 of Fukushima Prefecture evacuated to the places inside or outside the prefecture (May 2012). Out of those, the maximum of 62831 people (June 2012) evacuated out of the prefecture. (Note 3) Their evacuation types varied. Largely, they are divided into two types: a mandatory evacuation in response to the government's evacuation order and a voluntary evacuation based on people's discretion in the fear of invisible radioactivity contamination. (Note 4) The people under the mandatory evacuation order have moved their evacuation sites not only once but 4 times in average. (Note 5) It is observed that the evacuees have moved from one place to another extensively. And about $30 \%$ of the people under the mandatory evacuation order are separated from their family members. (Note 6)

In the dimension of evacuation behaviors, they varied as well. Some people were displaced by the mandatory evacuation order and evacuated inside or outside Fukushima Prefecture. Others evacuated inside or outside the prefecture as voluntary evacuation or could not leave their residence area at all for some reasons. The nuclear disaster accompanied by various evacuation behaviors like these provoked profound disagreement among the local residents about how to cope with invisible radioactive substances and mercilessly split their community. (Note 7) As nearly 6 years have passed since the GEJE, studies in attempt to paint the picture of various types of evacuees and specify the issues to be addressed have been accumulated. For example, Yamashita et al. (2013) describe their knowledge gained by supporting Tomioka town where the evacuation order was issued across the entire area and refer to the Japanese people's "lack of attitudes to understand" the situations surrounding the evacuees. As for the evacuees out of the prefecture, Takahashi and Taguchi (2014) illustrated the reality of a local community which supported mothers and their children (Note 8) who evacuated to Niigata Prefecture, which is adjacent to Fukushima Prefecture. And also Yoneda (2015) disclosed the conflict between the people evacuated from the metropolitan area and the local residents in Okayama Prefecture from the perspective on school lunches. Woo et al. (2015) defined the effect of the nuclear disaster by depicting the situation of the mothers and their children who evacuated within Fukushima Prefecture, particularly in Nakadori area. However, there has been less study on the effect of nuclear disaster on local communities, which is taken up in this research. Although this study deals with an example of a very small community in Japan, it is a valuable material in measuring the impact of a nuclear disaster on a local community. 


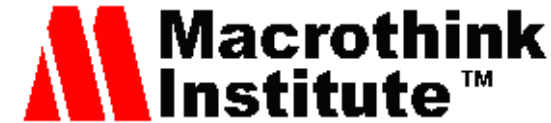

\section{Study Area and Investigation Method}

Iwaki City, the study area, which lies along the coastline of the Pacific, is in Fukushima Prefecture in Tohoku Region. "T" district in Abukuma Mountain Range, an hour-drive to the west from the center of Iwaki City, is the field of this study (see Figure 1).

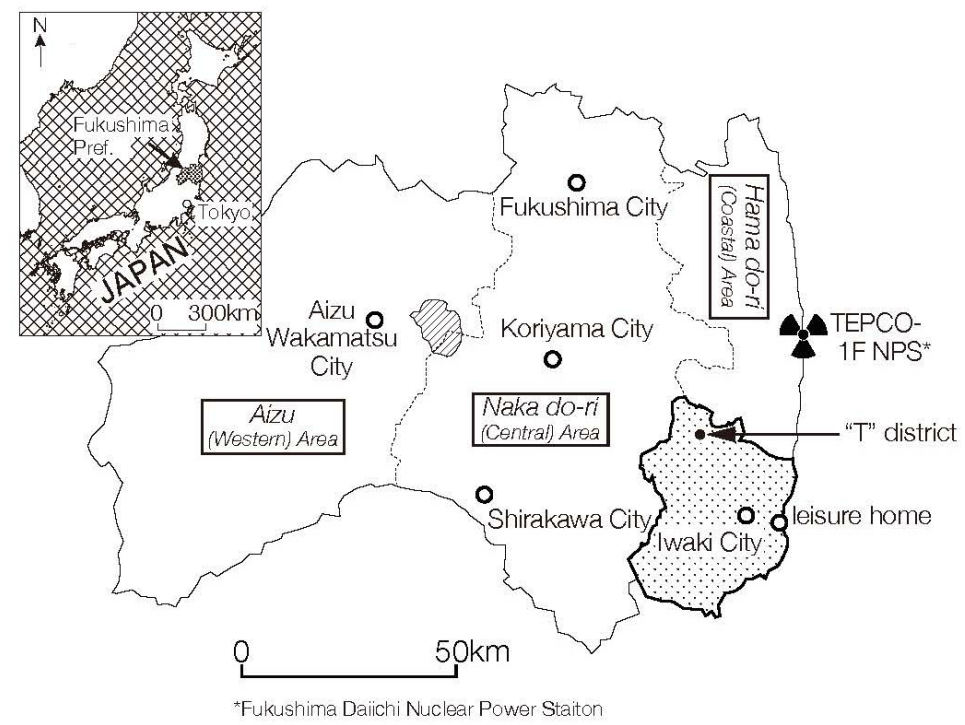

Figure 1. Study Area

Study area map of Fukushima Prefecture. Fukushima consists of three areas called "Hamadori", "Nakadori", and Aizu, "T" district is located in Iwaki City in Hamadori area

"T" district is a small community with a population of 44 people in 18 households (2011). In this district, $51 \%$ of the locals are aged 65 or older (2008) and there is no local aged 39 or younger. Though the main industry of this district is agriculture, many of the locals make their living also by forestry or by being employed by companies. In the hilly and mountainous area of Fukushima Prefecture, it is one of the districts with decreasing birthrate and aging population.

"T" district has been hosting university students from the Greater Tokyo Metropolitan Area with the aid of a subsidy from Fukushima Prefecture. The locals in "T" district have been making efforts to break away from the closed nature of their community, which is often seen in rural farming areas. Here, the locals and the hosted university students are working together to vitalize their community by growing rice or holding festivals. Hosting the university students has increased the opportunities for the locals to interact with each other, and it also has been beneficial for harmonizing their community.

"T" district is about $32 \mathrm{~km}$ (20 miles) away from TEPCO-1F NPS, which had a radiation accident in The Great East Japan Earthquake (GEJE). Due to the accident, there was a spreading concern that the radioactive substances would contaminate their district. In the measurement conducted in July 2011, 4 months after the accident, the average air dose rate $1 \mathrm{~m}$ in height from the ground surface was $1.3 \mu \mathrm{Sv}-0.33 \mu \mathrm{Sv} / \mathrm{h}$ and the radioactive cesium $(134 \mathrm{Cs}$ and $137 \mathrm{Cs})$ rate of the surface soil was about $800 \mathrm{~Bq} / \mathrm{kg}$. Though the district was 


\section{Macrothink}

close to TEPCO-1F NPS, the radioactive contamination found was a little.

As an investigation, interviews were conducted with the 10 locals who joined the community activities with the hosted university students. The interview results and their analysis are as described in the following sections.

\section{Behaviors of the Local Residents at the Occurrence of the Disaster}

When the earthquake struck " $T$ " district, they suffered a jolt with an intensity of lower 6 on the Japanese scale of 7. (Note 9) "T" district suffered only slight damages by the quake: (1) Some roofing tiles were found shaken off on the ground in 4 households, (2) Several houses were found tilting, (3) Plastic containers for kerosene were found fallen, (4) Some parts of mortar walls of a storehouse were found fallen, (5) A statue of Ninomiya Kinjiro (Note 10) was found fallen and damaged. Fortunately, no human damage was caused. The power supply was cut off from March 11th to March 13th. As for water supply, it was stopped during the power cut because pumping up of water required electricity. However, they could use fuel gas in a cylinder.

The 10 locals were struck by the earthquake in the following places: Local A was in central Iwaki City for a meeting. Local $\mathrm{B}$ was at home. Locals $\mathrm{C}$ and $\mathrm{H}$ were at their offices in town. Locals D, E, F, G, were in a leisure home in the coastal area for golden age club activities. Locals I and J were working in different places in the forest (see Figure 2).

After the earthquake, Local A drove back home and met Local B. Local C, as well, went back home with his co-worker. Locals D, E, F, G, who were in a leisure home in the coastal area, were sent home by the leisure home bus. The leisure home they had stayed at suffered damage by tsunami after they evacuated the home. Local $\mathrm{H}$ went back home after he dropped in at his office. Locals I and J drove back home.

All 10 locals were able to go back home by the end of the day in one way or another. This fact shows that the streets were only slightly damaged and it was possible for them to go back home by vehicles. Different from metropolitan areas, there was no return home refugee. 

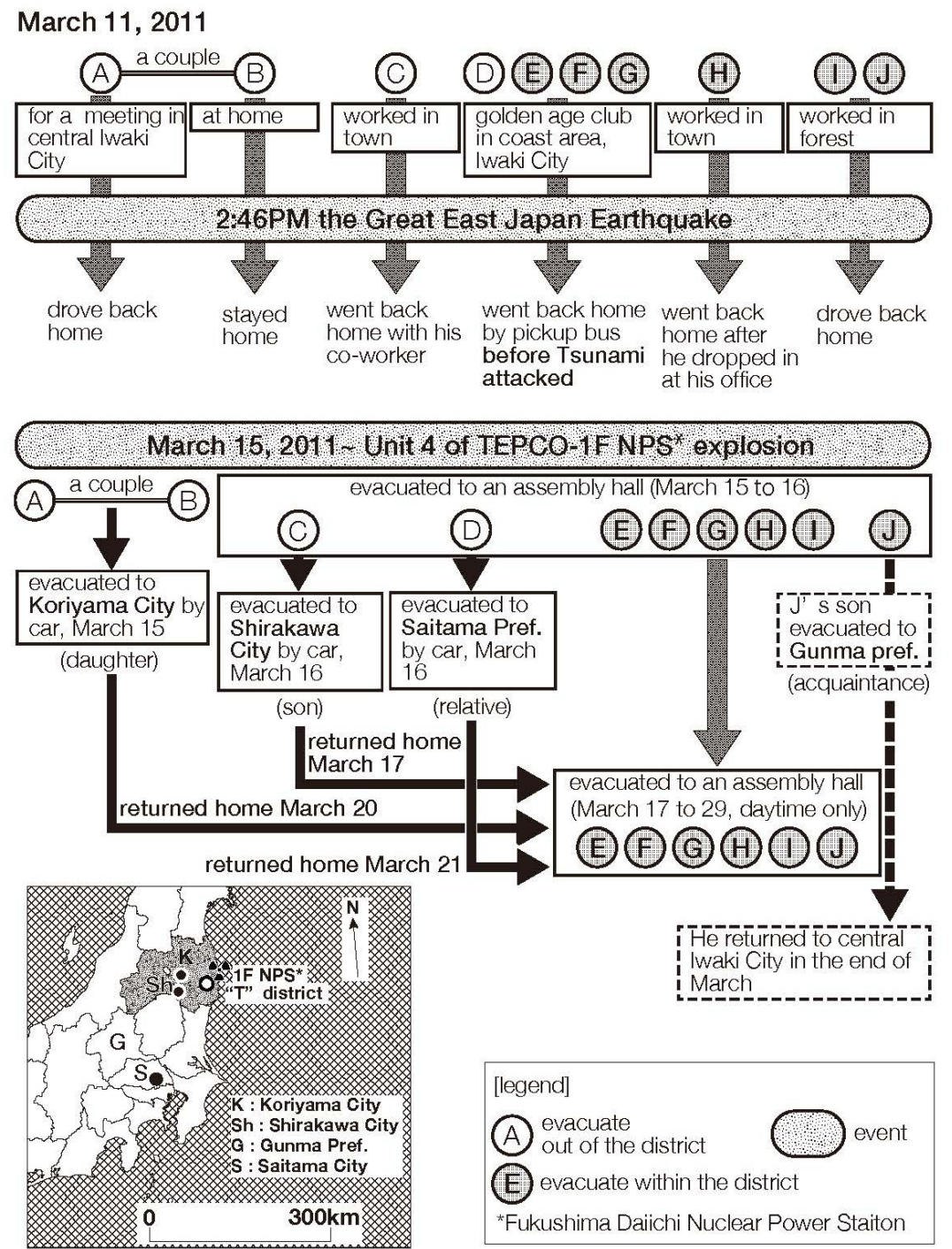

Figure 2. Evacuation Behaviors of the Locals in "T" district on and after March 11th, 2011 Source: Interviews with 10 locals in "T" district

The flowchart shows what the 10 locals did as voluntary evacuation for a month after the GEJE.

A map exhibiting their evacuation places (out of " $T$ " district) is attached on the bottom left.

\section{Evacuation Behaviors of the Locals after the Accident in TEPCO-1F NPS}

TEPCO-1F NPS, which had entirely lost power due to the effect of the earthquake and the tsunami, could no longer cool its nuclear reactor. On March 12th, the Unit 1 had a hydrogen explosion. On the $14^{\text {th }}$, the Unit 3 had a hydrogen explosion as well. And on the $15^{\text {th }}$, it ended up with the Unit 4 having a hydrogen explosion. As a result, it caused a serious situation that radioactive substances were released in the air. Looking at such situation, the Japanese government issued an evacuation order as "Indoor Standby" to the areas within a $20-30 \mathrm{~km}$ radius of TEPCO-1F NPS on March $15^{\text {th. }}$ (see Table 1) 
Table 1. TEPCO-1F NPS Accident

\begin{tabular}{|c|c|}
\hline Mar-11 & Major Event \\
\hline $\begin{array}{l}11^{\text {th }} \text { day of the } \\
\text { month }\end{array}$ & Great East Japan Earthquake power source lost, nuclear emergency declared \\
\hline \multirow[t]{2}{*}{$12^{\text {th }}$ day } & Evacuation order to residents within $10 \mathrm{~km}$ radius (later extended to $20 \mathrm{~km}$ radius) \\
\hline & Unit 1 (U1) venting starts, U1 hydrogen explosion, sea water injection \\
\hline $13^{\text {th }}$ day & U3 sea water injection \\
\hline $14^{\text {th }}$ day & U3 hydrogen explosion, U2 cooling system fails \\
\hline $15^{\text {th }}$ day & $\begin{array}{l}\mathrm{U} 2 \text { vent-off, } \mathrm{U} 4 \text { hydrogen explosion, } \mathrm{U} 2 \text { explosion-like noise, Stay indoors alert } \\
\text { within } 20-30 \mathrm{~km} \text { radius (rapid increase of dose at many locations) }\end{array}$ \\
\hline $16^{\text {th }}$ day & U3/U4 spent fuel cooling water boils up \\
\hline $17^{\text {th }}$ day & Aerial water spray by helicopters, water cannon spray from ground \\
\hline $18^{\text {th }}$ day & Nuclear and Industrial Safety Agency (NISA) declares INES Level 5 \\
\hline \multirow[t]{2}{*}{ Apr-11 } & NISA declares INES Level 7 \\
\hline & $\begin{array}{l}\text { Evacuation Area defined within Restricted Area near NPS(April 21), then } \\
\text { Deliberate Evacuation Area and Evacuation-Prepared Area in case of Emergency } \\
\text { defined (April 22) }\end{array}$ \\
\hline May-11 & NISA announces $\mathrm{U} 1,2$, and 3 of $1 \mathrm{~F}$ suffered meltdown \\
\hline
\end{tabular}

Sources: Sunday Mainichi emergent special issue 3 "Detailed Documentary of Fukushima Daiichi Meltdown," and Fukushima and NPS, Editing Bureau, Fukushima-Minpo Co., Ltd.

Chronological table of Tokyo Electrical Power Company Fukushima Daiichi Nuclear Power Station (TEPCO-1F NPS) accident. This table shows the worsening of the situation of TEPCO-1F NPS on and after March 11th, 2011.

"T" district, which is about $32 \mathrm{~km}$ away from TEPCO-1F NPS, was out of the Indoor Standby Zone. And the lifeline such as power, gas, and water supply in this district had been recovered by then. However, in response to the fact that the effect of the TEPCO-1F NPS accident was becoming serious, the locals of " $T$ " district started voluntary evacuation (see Figure 2).

Locals A and B, a married couple, evacuated to their daughter's house in Koriyama City on March $15^{\text {th }}$, when TEPCO-1F NPS Unit 4 had an explosion. The rest of the locals evacuated to an assembly hall in the district. On the $16^{\text {th }}$, Local $\mathrm{C}$ evacuated to his son's house in Shirakawa City in Fukushima Prefecture (Nakadori area). And Local D evacuated with his old parents to his relative's house in Saitama City in Saitama Prefecture. Total of 4 locals evacuated out of the district. The 6 locals, E through J, continued their evacuation in the assembly hall in the district. Though the evacuation date is unknown, Local $\mathrm{J}$ had his son 
whom he lived with evacuate to Gunma Prefecture.

From March 17th, several police officers were stationed in front of the assembly hall in the district for purpose of regulating entry in a $30 \mathrm{~km}$ radius of TEPCO-1F NPS. This made the locals recover their presence of mind. The 6 locals, who continued their evacuation in the assembly hall, started to get together in the hall only in the daytime to save their kerosene and gas. This continued until March 29th.

Out of the 4 locals (A, B, C, D), who had evacuated out of the district, Local C returned home on the $17^{\text {th }}$. And on the $20^{\text {th }}$, Locals A and B (a married couple) returned as well. Local D on the $21^{\text {st }}$. They finally started to spend daytime in the assembly hall in the district.

\section{Evacuation Effect on the Community}

All those who had evacuated out of the district eventually returned home. Unfortunately, it was not a happy ending though. They felt beholden to the rest of the locals as "escapees". And those who had evacuated to the assembly hall within the district regarded these people as "escapees". Why was this "dividing wall" made?

\subsection{Evacuation and Return Reasons of the Out-of-District Evacuees}

The locals who evacuated out of " $\mathrm{T}$ " district (hereafter, they are called "out-of-district evacuees") had various reasons for their evacuation. One of the reasons is a fear for radioactive contamination. It was natural that there was a concern among them that their district would be contaminated by radioactivity. Due to this fear and the fact that TEPCO-1F NPS was in a short distance away from their district, they decided to evacuate out of the district in response to the calls from their family members (children) or relatives living outside of "T" district. Other reasons are such as shortage of the fuel stored in their houses or concern about their parents' or their own health problems. Whatever the reason is, these people had a place to which they could evacuate outside the district. In other words, they are the people who could escape from the district. On the other hand, for those who had no place to go outside the district, evacuation outside of the district was impossible under the conditions where the government's evacuation order was not issued to their district.

What served as triggers for the out-of-district evacuees to return home? One of the reasons is that they gradually started to feel uneasy living with "other" families even though they were their own relatives' or children's. Another reason provided by Locals A, B, and C, who evacuated to Nakadori area, was the inconvenience caused by more snow accumulation in Nakadori area than in " $T$ " district in Hamadori area. Recently, it has been proved that the average air dose rate $1 \mathrm{~m}$ in height from the ground surface in "T" district is about the same or slightly lower than that in Nakadori area. Additionally, as described in Section 3, the stationing of the police officers in front of the assembly hall in "T" district was provided as another reason for their returning home.

For these reasons, the out-of-district evacuees decided to return home (hereafter, they are called "returnees"), but it provoked conflicts with the locals who had been consistently staying inside the district during their evacuation. 


\subsection{Reasons for the Evacuation within the District}

In the same way that the returnees had various reasons for their out-of-district evacuation, the locals who continued to evacuate within the district also had various reasons. The reasons they evacuated within the district are as follows: Some of them were ordered by their companies to stay home. Others could not abandon their livestock raised within the site of their residence. There were also some locals who could not find anywhere else to go because of their pet animals or personal matters though they were urged to get out of the district by their relatives.

From the described above, it can be inferred that more than a few locals could not evacuate out of the district even though they wanted to in the fear of radioactive contamination. (Note 11) The out-of-district evacuees returned home where the rest had not been able to get out of the district against their will. This can be one of the reasons why the conflict was caused between these two groups of people, those who could evacuate out of the district and those who did not or could not.

\section{Attempts to Temper the Conflict in the District}

In " $T$ " district, where the relationship among the locals is deep, it is impossible for them to live within the community with the conflict unsolved. (Note 12) Though it was difficult to get their community back to what it had been, at least, tempering the conflict was necessary for both the returnees and those who had consistently stayed in the district.

The first action in attempt to temper the conflict was taken by the returnees. They took some roles in the community. In "T" district, daytime-evacuation in the assembly hall continued till March $29^{\text {th }}$. And the returnees actively took roles such as hot meal service.

Right after the GEJE, in the relationship between the "escapees (those who evacuated out of the district)" and the "non-escapees (those who did not or could not)", the "escapees" were in a vulnerable position. Therefore, a certain attempt to move "non-escapees" to accept "escapees" was necessary in the community. In the interviews with the returnees, some said that they had no choice but to endure in silence even when they knew "non-escapees" spoke badly of them. Until they were reconciled to some extent, the returnees had been in severe environment.

In addition to the attempt made within the district, an attempt provided from outside of the district also helped temper the conflict in the community. As mentioned in the previous section, the locals in "T" district were making efforts to vitalize their community by hosting the university students from the Greater Tokyo Metropolitan Area (hereafter, this is called "university student activities"). After the GEJE, for the purpose of continuing the university student activities, the community needed to get together and make an arrangement again to host the students. These activities had been carried out by both the returnees and those who consistently stayed within the district. In the situation where the conflict over the evacuation still remained in the community, it was difficult for them to collaborate on the university student activities as before. As a way out of the situation, those who had consistently stayed within the district decided to "superficially" accept the returnees in order to continue the 
university student activities and make an arrangement for it. As a result of their efforts, they succeeded in hosting the students and providing them with agricultural experience programs even in 2011, the year of the GEJE.

This fact shows that the internal attempt made by the returnees and the external effect of the university student activities served as triggers for tempering the community conflict.

\section{Conclusion}

This study, based on a case study of a small rural community in Japan, clarified the existence of community conflict caused by the nuclear disaster and how the conflict was tempered. The findings in this study are as follows: A nuclear disaster can split personal relationship in the local communities. It was found that not only the difference in the locals' attitudes toward radioactivity but also their various evacuation behaviors caused the community conflict.

In the earlier stage after the GEJE, "escapees" and "non-escapees" were in different positions. The study results shows that the "escapees", who were in a weaker position, had to work on "non-escapees" to accept them again in the community when they tried to return home.

As for tempering the community conflict, communicating with the hosted university students can be considered as one of the help. Since the community members wanted to continue the university student activities even after the GEJE, it served as an opportunity for them to collaborate together. It may safely be said that the community situation like this helped temper the conflict.

Nearly 6 years have passed since the GEJE. The community in "T" district has now recovered its calmness. Though the conflict described above has not been completely eliminated, obvious collisions have been decreasing. The locals in "T" district live their everyday life with unsolved conflict kept in their mind.

\section{Acknowledgements}

The author wishes to acknowledge the members of Rissho University Kumagaya Geographical Research Association for their assistance with this study. I am grateful to Tokiko Kai for English interpretation. I would also like to thank the residents of "T" district. This work was supported by JSPS KAKENHI Grant Numbers JP25220403, JP15K11927.

\section{References}

Takagi, A. (2015). Restoration from Nuclear Disaster and Geography. Chiri (Geography). 60(1), 28-31. [published in Japanese]

Takahashi, W., \& Taguchi, T. (2014). I want to keep supporting my mother: Evacuation from Nuclear Power Plant and Local Communities in Niigata Prefecture. Tokyo: Honnoizumisya. [published in Japanese]

The Institute of Rehabilitation at Fukushima University (2013). The basic report of the disaster recovery questionnaire survey for residents of Futaba district. [published in Japanese]. 
Woo, C. U., Kayo, Matutani, M., \& Sakaguchi, Y. (2015). Endless Hours of Victims: Impact of Nuclear Accident on Mothers and their Children in Nakadori area in Fukushima Prefecture. Fukuoka: Sekifusha.[published in Japanese].

Yamashita, Y. I., Takashi, \& Sato, A. (2014). Inhumane Restoration: Concerning Evacuation from Nuclear Power Plant and the People's lack of attitudes to understand). Tokyo: Akashi shoten. [published in Japanese].

Yoneda, M. (2015). Conflict between "Voluntary Refugees" from Nuclear Disaster and Local Residents in Okayama Prefecture: With Special Attention to Public School Lunch in Primary and Junior High-schools. Annals of Ochanomizu Geographical Society, 54, 11-20 [published in Japanese].

\section{Notes}

Note 1. A region located in the northeastern part of Japan's main land. This region consists of 6 prefectures. Iwate, Miyagi, and Fukushima Prefectures, located along the coastline of the Pacific, suffered particularly significant damages in the GEJE.

Note 2. A region located in the southeastern part of Japan's main land along the Pacific. This region consists of the Metropolis of Tokyo and other 6 prefectures. The most of the region is called Kanto plain and the western and the northern parts of this region are fringed with mountains. The nuclear fallout from TEPCO-1F NPS created hot spots in the mountain areas and a part of Kanto plain.

Note 3. See the homepage of Fukushima Prefecture: http://www.pref.fukushima.lg.jp/site/portal/list271.html (browsed on December 29th, 2016). According to the latest data, the total number of the evacuees is 84289 (as of November 2016). 40059 people of these are out of the prefecture as of December 2016.

Note 4. The process of these types of evacuation is detailed in Yamashita et al. (2013).

Note 5. According to the Institute of Rehabilitation at Fukushima University (2013)

Note 6. See Note 5.

Note 7. According to Takagi (2015), the differences in the residents' attitudes toward radioactivity created a split among family members, community members, different generations or genders. It is represented in their evacuation behaviors. In addition, the presence or absence of the compensation also created a split among the victims. (Yamashita et al. 2013, Woo et al. 2015)

Note 8. This is called "mother-and-child-only evacuation"'boshi-hinan". To make their living, fathers stay in their residence in Fukushima Prefecture or wherever while mothers and their children evacuate out of the prefecture so that the children can be protected from radioactive contamination.

Note 9. A record in Iwaki City. 


\section{Macrothink}

Journal of Asian Development

ISSN 2377-9594 2017, Vol. 3, No. 1

Note 10. A practical farmer in the end of Edo era $(1787$ - 1856).

Another name: Sontoku Ninomiya. His statues were built in many elementary schools in Japan in early Showa era.

Note 11. In addition to this, some said that the out-of-district evacuees had left the district without letting them know. Such behavior can be considered as a reason of the community conflict.

Note 12. In many rural farming areas in Japan, the local communities still have culture of collaborative work. Because of this, if the conflict among the locals remains unsolved, the social function of the community will be lowered.

\section{Copyright Disclaimer}

Copyright for this article is retained by the author(s), with first publication rights granted to the journal.

This is an open-access article distributed under the terms and conditions of the Creative Commons Attribution license (http://creativecommons.org/licenses/by/3.0/). 